\title{
Care Seeking Determinants among Adolescents in Lagos, Nigeria
}

\author{
Onajole Adebayo $\mathrm{T}^{1}$, Dolapo Clement $\mathrm{D}^{1}$, Osunkalu Vincent $\mathrm{O}^{2^{*}}$, Uwem Esite ${ }^{3}$, \\ Adenike Esite ${ }^{3}$, Odiakosa Adebunmi ${ }^{3}$ and Okpechi Felix-Mary $\mathrm{U}^{4}$
}

\author{
1Department of Community Health and Primary Care, Lagos University Teaching Hospital, Idi-Araba, Lagos, \\ Nigeria, ${ }^{2}$ Department of Haematology and Blood Transfusion, College Of Medicine, University Of Lagos, \\ Nigeria, ${ }^{3}$ Action Health Incorporated - AHI, ${ }^{4}$ Department of Epidemiology, Medical Statistics and \\ Environmental Health, Faculty of Public Health, University of Ibadan
}

\begin{abstract}
Adolescents often lack basic reproductive health information, knowledge, and access to affordable confidential health services for reproductive health. This cross-sectional descriptive study aimed to examine the care seeking determinants of adolescents accessing the adolescent friendly services at the Action Health Incorporated Adolescent Clinic in Lagos, Nigeria. A structured interviewer administered questionnaire was used to elicit information about demographics; past medical history; family history; reproductive/sexual history. The study was explained to the adolescents and their consent was obtained before interviewing them. Data analysis was done using SPSS Version 15. A multiple logistic regression was used to model the relationship between client facility-use status and selected individual characteristics. Odd ratio and confidence interval were computed, and a level of significance of 0.05 was chosen. The mean age of the adolescent was $16.3 \pm 2.8$ years. A high proportion (77.5\%) of them reported not to be sexually active. The logistic regression model identified preferred/adopted contraceptive during last visit $(\mathrm{OR}=0.60,95 \% \mathrm{Cl}=$ 0.35 to 1.00 ), sexual status ( $O R=0.40,95 \%$ C.I 0.27 to 0.60 ) and religion $\mathrm{OR}=2.04,95 \% \mathrm{C} . \mathrm{I}=1.43$ to 2.92) as determinants of adolescents' booking for a re-visit to the clinic. The determinants of adolescents' booking for re-visit to Action Health Incorporated clinic were preferred/adopted contraceptive during last visit, sexual status and religion. The implication of this may be that those who did not book for re-visits felt that they were not adequately benefiting from the services rendered at the clinic. More varieties of adolescent friendly services that meet the needs of all adolescents should be included at the clinic.
\end{abstract}

Key words: Adolescent, Care seeking determinant, Confidential health services, Reproductive health

Received 23 March 2010/ Accepted 1 June 2010

\section{INTRODUCTION}

Adolescents are prone to suffering from reproductive and sexual health, nutritional, mental and behavioural problems (Nath and Garg, 2008). They account for almost about $44 \%$ of Nigeria's population and have been defined as young people between the ages of 10-19 years (WHO, 1998). It has also been defined by the United Nations as the stage of life during which individuals reach sexual maturity; a period of transition from puberty to maturity. Nigerian adolescents like their counterparts around the globe are sexually active (Oransaye and Odiase, 1983).

In many countries, the majority of people: married or unmarried initiate sexual activity during adolescence (Mensch et al., 1998). However, during this stage of their life, adolescents face special challenges with regard to access to reproductive health services (Segun, 2006). Many adolescents do not feel comfortable in discussing reproductive health with parents (PATH, 1999). 
They may also experience resistance or hostility and bad attitudes from adults when young people attempt to obtain the reproductive health information and services they need. These circumstances can be attributed to a number of social, religious, cultural, economic, and genderrelated factors, many of which are avoidable.

In addition to barriers, the decision to utilize health services is determined by the nature of the problem and the circumstances of the individual and the family. Knowing about the care seeking determinants of adolescents can help providers be more responsive to their reproductive health care needs since they have specific reproductive health needs based on their age, sex, marital status, and socioeconomic situation. They may need different types of care, depending on whether they are still in school, out of school or married. Besides, adolescents usually have lower social status and receive little or no legal protection. They may also be at greater risk of sexual violence especially females (Creel and Perry, 2003). However, various factors that affect adolescents' accessibility to reproductive health care may include the importance they give to confidentiality; clinic environment; provider's attitudes and availability of medicines.

Services are adolescent friendly if they have policies and attributes that attract adolescents to the facility or programme, provide a comfortable and appropriate setting for serving youth, meet the needs of young people and are able to retain their youth clientele for follow-up and repeated visits (UNESCO, 1999). Thus, this study aimed to examine the care seeking determinants of adolescents attending the adolescent friendly services at the Action Health Incorporated, Lagos, Nigeria.

\section{MATERIALS AND METHODS}

\section{Study Design and Location}

This was a cross-sectional descriptive study of male and female adolescents attending Action Health Incorporated clinic in Lagos, Nigeria. Lagos is an urban city and the commercial nerve centre of Nigeria. It was also the former capital of the Federal Republic of Nigeria. Action Health Incorporated is community based adolescent friendly center established within the context of health service provision for all segments of the population, providing equitable and confidential health services as recommended by the WHO. In line with the current guidelines from the United State society for Adolescent Medicine, emphasise is placed on maintaining confidentiality, cost, youth participation, evidence based treatment, and multi-sectoral collaboration and the scope of activity covers a wide range of health issues.

\section{Study Population and Assessment Procedure}

Six thousand and eighty-one (6081) unmarried young people that attended the youth-friendly clinic between 1999 and 2002 were enrolled in the study. A structured interviewer administered questionnaire was used to elicit information about demographics; past medical history; family composition; reproductive/sexual health; family and psychological history; sexual abuse history; reason/concerns for visit; drug use history; condom/contraceptive use history. The questionnaire was designed to explain and predict factors responsible for young peoples' use of youth-friendly clinic in developing nations as well as their reproductive health behaviour. The outcome measure was based on client facility-use status (defined here as whether the adolescents booked or did not book for a re-visit). The major independent/explanatory variables are sex of respondents; ever had sex; type of sex (oral, anal, vaginal); age of respondent; age at first sexual intercourse; family structure; nature of family (whether parents are living together or not); category of respondent (in-school and outschool); religion, ethnic group; reproductive tract infection; contraceptives options preferred; ever had a HIV test; source of information and who the respondent lives with; concern of client; frequency of sex; number of sexual partners and use of contraceptive for last sexual intercourse. The study was explained to the adolescents and their consent was obtained before interviewing them.

\section{Data Management}

Data analysis was done using SPSS Version 15 for Windows. Logistic regression was used to model the relationship between client facility-use status and selected individual characteristics. Categorical variables were summarized using frequencies while numeric data were described using means and standard deviations. Cross tabulation of some selected independent variables and outcome variable were done, odd ratio and confidence interval were computed. $\mathrm{A}$ level of significance was fixed at 0.05 . 


\section{RESULTS}

Table 1: Characteristics of Respondents

\begin{tabular}{|c|c|c|}
\hline Variable & Frequency $(n=6081)$ & Percent \\
\hline \multicolumn{3}{|l|}{ Age (year) } \\
\hline $10-14$ & 1472 & 24.2 \\
\hline $15-19$ & 4044 & 66.5 \\
\hline $20-24$ & 565 & 9.3 \\
\hline Mean age & $16.3 \pm 2.8$ & \\
\hline \multicolumn{3}{|l|}{ Sex } \\
\hline Male & 2184 & 35.9 \\
\hline Female & 3897 & 64.1 \\
\hline \multicolumn{3}{|l|}{ Category } \\
\hline In school & 5789 & 95.2 \\
\hline Out of school & 292 & 4.8 \\
\hline \multicolumn{3}{|l|}{ Religion } \\
\hline Christianity & 4403 & 72.4 \\
\hline Islam & 1678 & 27.6 \\
\hline \multicolumn{3}{|l|}{ Ethnicity } \\
\hline Igbo & 1009 & 16.6 \\
\hline Yoruba & 1569 & 25.8 \\
\hline Others & 3503 & 57.6 \\
\hline \multicolumn{3}{|l|}{ Type of family } \\
\hline Monogamous & 4305 & 70.8 \\
\hline Polygamous & 1435 & 23.6 \\
\hline Single parent & 341 & 5.6 \\
\hline \multicolumn{3}{|l|}{ Respondent live with } \\
\hline Both parents & 3831 & 63.0 \\
\hline Single parent & 1216 & 20.0 \\
\hline Extended family member & 1034 & 17.0 \\
\hline \multicolumn{3}{|l|}{ Source of information } \\
\hline Friend & 4117 & 67.7 \\
\hline Sibling & 578 & 9.5 \\
\hline Teacher/principal & 189 & 3.1 \\
\hline Parents & 79 & 1.3 \\
\hline AHI staff & 116 & 1.9 \\
\hline Peer educator & 97 & 1.6 \\
\hline Health worker & 711 & 11.7 \\
\hline Media & 170 & 2.8 \\
\hline Others & 24 & 0.4 \\
\hline \multicolumn{3}{|c|}{ Reasons for using health facility } \\
\hline General health & 4743 & 78.0 \\
\hline Sexual health concern & 590 & 9.7 \\
\hline Laboratory investigations & 12 & 0.2 \\
\hline Menstrual irregularities & 152 & 2.5 \\
\hline Sexual abuse & 18 & 0.3 \\
\hline Reproductive tract infections & 401 & 6.6 \\
\hline Pregnancy options & 55 & 0.9 \\
\hline Counseling & 110 & 1.8 \\
\hline \multicolumn{3}{|c|}{ Other characteristics (multiple responses) } \\
\hline Parent living together & 4427 & 72.8 \\
\hline Ever had RTI infection & 797 & 13.1 \\
\hline Ever had HIV test & 61 & 1.0 \\
\hline Respondent is a booked client & 2505 & 41.2 \\
\hline
\end{tabular}


Table 1 shows the characteristics and distribution of never-married youths. The majority $(64.1 \%)$ were females. Most of the respondents were in school (95.2\%) and (70.8\%) were from monogamous homes with only $5.6 \%$ reporting to be from single parents. $72.8 \%$ of parents live together. Only $17.0 \%$ of the young people reported living with extended family members while $20.0 \%$ live with single parents (either mother or father). About a quarter $(25.8 \%)$ of the young people were Yorubas with only $16.6 \%$ Igbos while other tribes including Hausas, Edos, Ibibios, Efiks and Igalas account for $57.6 \%$. About two-thirds $(66.5 \%)$ of the facility users were within ages 15 -
19 years; $24.2 \%$ within ages of 10 and 14 years while only $9.3 \%$ were aged $20-24$ years old. The mean age of the young people was $16.3 \pm 2.8$ years. A high proportion (77.5\%) of the young people reported not sexually active. Only $25.5 \%$ of the never married youths reported to have ever had sexual intercourse. The mean age of first sexual initiation was $15.5 \pm 3.0$ years. The majority $(83.6 \%)$ of those that were sexually active engaged in sexual intercourse at least once a week while $12.2 \%$ and $4.2 \%$ reported frequency of sexual intercourse to be at least once a month and once a year respectively, with the majority $(97.8 \%)$ engaging in vaginal sexual intercourse.

Table 2: Sexual History of Respondents

\begin{tabular}{|c|c|c|}
\hline Variable & Frequency & Percent \\
\hline \multicolumn{3}{|l|}{ Ever had sex $(n=6081)$} \\
\hline Yes & 1551 & 25.5 \\
\hline No & 4530 & 74.5 \\
\hline \multicolumn{3}{|l|}{ Age at first sex $(n=1551)$} \\
\hline $5-9$ & 84 & 5.4 \\
\hline $10-14$ & 349 & 22.5 \\
\hline $15-19$ & 1082 & 69.8 \\
\hline $20-24$ & 36 & 2.3 \\
\hline Mean age at first sex & $15.5 \pm 3.0$ & \\
\hline \multicolumn{3}{|l|}{ Sexual status $(n=1551)$} \\
\hline Sexually active & 349 & 22.5 \\
\hline Not sexually active & 1202 & 77.5 \\
\hline \multicolumn{3}{|l|}{ Number of sexual partners $(n=349)$} \\
\hline $1-2$ & 306 & 87.7 \\
\hline $3-4$ & 35 & 9.9 \\
\hline$\geq 5$ & 8 & 2.4 \\
\hline \multicolumn{3}{|l|}{ Type of sex $(n=349)$} \\
\hline Vaginal & 341 & 97.8 \\
\hline Anal/oral/fingering & 8 & 2.2 \\
\hline \multicolumn{3}{|l|}{ Frequency of $\operatorname{sex}(n=349)$} \\
\hline At least once a week & 292 & 83.6 \\
\hline At least once a month & 42 & 12.2 \\
\hline At least once a year & 15 & 4.2 \\
\hline \multicolumn{3}{|l|}{ Use contraceptive $(n=349)$} \\
\hline Yes & 143 & 40.9 \\
\hline No & 206 & 59.1 \\
\hline \multicolumn{3}{|l|}{ Preferred contraceptive $(n=143)$} \\
\hline Any of condom, pill, implants (VFT) & 26 & 18.2 \\
\hline Condom alone & 27 & 18.9 \\
\hline Abstinence & 90 & 62.9 \\
\hline
\end{tabular}

However, $59.1 \%$ had not used any contraceptive for their last sexual intercourse. On the number of sexual partners, most $(87.7 \%)$ of them reported 1 or 2 partners while only $2.4 \%$ reported 5 or more partners. Only $13.1 \%$ of the youths have ever had reproductive tract infections. Only $1.0 \%$ have ever had HIV test done. The majority $(67.7 \%)$ of the young people received information about the youth-friendly clinic from friends. The major reason given for attending the clinic was for general health problems $(78.1 \%)$. Others reasons were sexual health $(9.7 \%)$ and reproductive tract infections $(6.7 \%)$. However, only $41.2 \%$ of the never married youths booked for follow-up. 
Table 3: Associations between Client Facility-use Status and Selected Characteristics

\begin{tabular}{|c|c|c|c|c|c|c|}
\hline \multirow[t]{2}{*}{ Variable } & \multicolumn{2}{|c|}{ Booking status for a re-visit } & \multirow[t]{2}{*}{ OR } & \multicolumn{2}{|c|}{$95 \% \mathrm{Cl}$} & \multirow[t]{2}{*}{$\boldsymbol{P}$} \\
\hline & $\begin{array}{l}\text { Booked } \\
(n=2505)\end{array}$ & $\begin{array}{c}\text { Did not book } \\
(n=3576)\end{array}$ & & Lower & Upper & \\
\hline \multicolumn{7}{|l|}{ Age } \\
\hline $10-14$ & $576(39.1)$ & $896(60.9)$ & 0.86 & 0.79 & 1.01 & 0.07 \\
\hline $15-19$ & $1699(42.0)$ & $2345(58.0)$ & 1.11 & 0.99 & 1.24 & 0.07 \\
\hline $20-24$ & $230(40.7)$ & $335(59.3)$ & 0.98 & 0.82 & 1.17 & 0.81 \\
\hline \multicolumn{7}{|l|}{ Sex } \\
\hline Male & 904 (41.4) & $1280(58.6)$ & 1.01 & 0.91 & 1.13 & 0.81 \\
\hline Female & $1601(41.1)$ & $2296(58.9)$ & 0.99 & 0.89 & 1.10 & 0.81 \\
\hline \multicolumn{7}{|l|}{ Category } \\
\hline In school & $2391(41.3)$ & 3398 (58.7) & 1.10 & 0.86 & 1.41 & 0.44 \\
\hline Out of school & $114(39.0)$ & $178(61.0)$ & 0.91 & 0.71 & 1.71 & 0.44 \\
\hline \multicolumn{7}{|l|}{ Religion } \\
\hline Christianity & $1563(35.5)$ & $2840(64.5)$ & 0.43 & 0.38 & 0.48 & 0.00 \\
\hline Islam & $942(56.1)$ & $736(43.9)$ & 2.33 & 2.07 & 2.61 & 0.00 \\
\hline \multicolumn{7}{|l|}{ Ethnicity } \\
\hline Igbo & $446(44.2)$ & $563(55.8)$ & 1.16 & 1.01 & 1.33 & 0.03 \\
\hline Yoruba & $646(41.2)$ & $923(58.8)$ & 1.00 & 0.89 & 1.13 & 0.99 \\
\hline Others & 1413(40.3) & 2090(59.7) & 0.92 & 0.83 & 1.02 & 0.11 \\
\hline \multicolumn{7}{|l|}{ Type of family } \\
\hline Monogamous & $1739(40.4)$ & 2566 (59.6) & 0.89 & 0.80 & 1.00 & 0.05 \\
\hline Polygamous & $611(42.6)$ & $824(57.4)$ & 1.08 & 0.95 & 1.22 & 0.22 \\
\hline Single parent & $155(45.5)$ & $186(54.5)$ & 1.20 & 0.96 & 1.51 & 0.10 \\
\hline \multicolumn{7}{|l|}{ Respondent live with } \\
\hline Both parents & $1540(40.2)$ & 2291 (59.8) & 0.90 & 0.80 & 1.00 & 0.04 \\
\hline Single parent & 527 (43.3) & $689(56.7)$ & 1.12 & 0.98 & 1.27 & 0.09 \\
\hline Extended family member & $438(42.4)$ & $596(57.6)$ & 1.06 & 0.92 & 1.22 & 0.40 \\
\hline \multicolumn{7}{|l|}{ Reasons for using the facility } \\
\hline General health & $1708(36.0)$ & $3035(64.0)$ & 0.38 & 0.34 & 0.43 & 0.00 \\
\hline Sexual health concern & $317(53.7)$ & $273(46.3)$ & 1.75 & 147 & 2.09 & 0.00 \\
\hline Laboratory investigations & $6(50.0)$ & $6(50.0)$ & 1.43 & 0.41 & 4.99 & 0.54 \\
\hline Menstrual irregularities & $111(73.0)$ & $41(27.0)$ & 4.00 & 2.75 & 5.84 & 0.00 \\
\hline Sexual abuse & $9(50.0)$ & $9(50.0)$ & 1.43 & 0.52 & 3.92 & 0.45 \\
\hline Reproductive tract infections & $247(61.6)$ & $154(38.4)$ & 2.43 & 1.96 & 3.01 & 0.00 \\
\hline Pregnancy options & $44(80.0)$ & $11(20.0)$ & 5.79 & 2.89 & 11.91 & 0.00 \\
\hline Counseling & $63(57.3)$ & $47(42.7)$ & 1.94 & 1.30 & 2.89 & 0.00 \\
\hline \multicolumn{7}{|l|}{ Characteristics of respondents } \\
\hline Parent living together & $586(40.5)$ & $861(59.5)$ & 0.96 & 0.85 & 1.09 & 0.54 \\
\hline Ever had RTI infection & $342(42.9)$ & $455(57.1)$ & 1.08 & 0.93 & 1.26 & 0.29 \\
\hline Ever had HIV test & $33(54.1)$ & $28(45.9)$ & 1.69 & 0.99 & 2.89 & 0.04 \\
\hline Ever had sex & $676(43.6)$ & $875(56.4)$ & 1.50 & 1.33 & 1.68 & 0.00 \\
\hline Sexually active & $169(48.4)$ & $180(51.6)$ & 1.46 & 1.14 & 1.87 & 0.00 \\
\hline Age at first sex & & & & & & \\
\hline $5-9$ & $29(34.5)$ & $55(65.5)$ & 0.66 & 0.40 & 1.06 & 0.07 \\
\hline $10-14$ & $155(44.4)$ & $194(55.6)$ & 1.02 & 0.80 & 1.31 & 0.87 \\
\hline $15-19$ & $481(44.5)$ & $601(55.5)$ & 1.06 & 0.85 & 1.32 & 0.61 \\
\hline $20-24$ & $18(50.0)$ & $18(50.0)$ & 1.28 & 0.63 & 2.59 & 0.47 \\
\hline Number of sexual partners & & & & & & \\
\hline $1-2$ & $149(48.7)$ & $157(51.3)$ & 1.09 & 0.55 & 2.17 & 0.79 \\
\hline $3-4$ & $14(40.0)$ & $21(60.0)$ & 0.68 & 0.32 & 1.47 & 0.29 \\
\hline$\geq 5$ & $6(75.0)$ & $2(25.0)$ & 3.28 & 0.59 & 23.81 & 0.13 \\
\hline Type of sex & & & & & & \\
\hline Vaginal & $166(48.7)$ & $175(51.3)$ & 1.58 & 0.32 & 8.48 & 0.53 \\
\hline Anal/oral/fingering & $3(37.5)$ & $5(62.5)$ & 0.63 & 0.12 & 3.09 & 0.53 \\
\hline Use contraceptive for this Sex & $80(55.9)$ & $63(44.1)$ & 1.67 & 1.06 & 2.63 & 0.02 \\
\hline Frequency of sex & & & & & & \\
\hline At least once a week & $138(53.4)$ & $154(46.6)$ & 0.75 & 0.41 & 1.38 & 0.33 \\
\hline At least once a month & $22(52.4)$ & $20(47.6)$ & 1.20 & 0.60 & 2.39 & 0.58 \\
\hline At least once a year & $9(60.0)$ & $6(40.0)$ & 1.63 & 0.52 & 5.29 & 0.36 \\
\hline Preferred contraceptive & & & & & & \\
\hline Any of condom, pill, VFT & $13(50.0)$ & $13(50.0)$ & 0.75 & 0.29 & 1.89 & 0.50 \\
\hline Condom alone & $14(51.9)$ & $13(48.1)$ & 0.82 & 0.30 & 2.04 & 0.63 \\
\hline Abstinence & $40(44.4)$ & $50(55.6)$ & 0.26 & 0.11 & 0.58 & 0.00 \\
\hline
\end{tabular}


Table 3 presented bi-variable relationship of client facility-use status and selected individual characteristics for never-married youths. The factors that were significantly associated with revisit to the health facility among the youths were: religion, ethnicity, who the youth live with, reasons for visiting the facility, whether youth have ever had sex, whether they were sexually active, use of contraceptive for the last intercourse and the preferred/adopted contraceptive. The logistic regression model in Table 4 identified three factors as determinants of young peoples' ability to re-visit the health care facility. The factors were the preferred/adopted contraceptive during last visit, sexual status and religion. Never-married youths who adopted abstinence as their contraceptive option during the last visit were less likely to re-visit the youth friendly clinic than those who prefer any of condom or pill (OR $=0.60,95 \%$ C.I $=0.35$ to 1.00 ). Also, not sexually active nevermarried youths were less likely to make a re-visit to the health facility after first consultation than sexually active youths $(\mathrm{OR}=0.40,95 \% \mathrm{C} . \mathrm{I}=0.27$ to 0.60$)$. The never-married Muslim youths are about 2 times more likely to make a re-visit to the health care facility than Christian Never-married youths $(\mathrm{OR}=2.04,95 \% \mathrm{C} . \mathrm{I}=1.43$ to 2.92$)$.

\section{Table 4: Logistic Regression Model of Client Facility-use Status of Respondents}

\begin{tabular}{|c|c|c|c|c|c|c|}
\hline \multirow[t]{2}{*}{ Variable } & \multirow[t]{2}{*}{ Coefficient } & \multirow{2}{*}{$\begin{array}{l}\text { Standard } \\
\text { error }\end{array}$} & \multirow{2}{*}{$\begin{array}{l}\text { Odd } \\
\text { ratio }\end{array}$} & \multicolumn{2}{|c|}{$95 \% \mathrm{Cl}$} & \multirow[t]{2}{*}{$\mathbf{p}$} \\
\hline & & & & Lower & Upper & \\
\hline \multicolumn{7}{|l|}{ Religion } \\
\hline Islam/Christianity & 0.71 & 0.18 & 2.04 & 1.43 & 2.92 & 0.00 \\
\hline \multicolumn{7}{|l|}{ Ethnicity } \\
\hline Igbo/Others & 0.17 & 0.22 & 1.18 & 0.78 & 1.81 & 0.44 \\
\hline Yoruba/Others & -0.05 & 0.17 & 0.95 & 0.68 & 1.34 & 0.78 \\
\hline \multicolumn{7}{|l|}{ Type of family } \\
\hline Polygamous/Monogamous & -0.11 & 0.18 & 0.90 & 0.64 & 1.27 & 0.55 \\
\hline Single parent/Monogamous & 0.46 & 0.34 & 1.58 & 0.82 & 3.05 & 0.18 \\
\hline \multicolumn{7}{|l|}{ Respondent live with } \\
\hline Single parent/Both parents & -0.06 & 0.23 & 0.94 & 0.60 & 1.46 & 0.78 \\
\hline Extended family member/Both parents & -0.10 & 0.20 & 0.90 & 0.61 & 1.34 & 0.61 \\
\hline \multicolumn{7}{|l|}{ Characteristics of respondents } \\
\hline Never had HIV test/Ever had HIV test & -0.82 & 0.53 & 0.44 & 0.16 & 1.23 & 0.12 \\
\hline Never had sex/Ever had sex & 1.62 & 1.32 & 5.07 & 0.38 & 67.22 & 0.22 \\
\hline Not sexually active/Sexually active & -0.92 & 0.21 & 0.40 & 0.27 & 0.60 & 0.00 \\
\hline \multicolumn{7}{|l|}{ Preferred contraceptive } \\
\hline Condom alone/Condom, pill & 0.06 & 0.26 & 1.06 & 0.64 & 1.76 & 0.83 \\
\hline Abstinence/Condom, pill & -0.52 & 0.27 & 0.60 & 0.35 & 1.00 & 0.05 \\
\hline
\end{tabular}

\section{DISCUSSION}

Attendance at Action Health Incorporated is voluntary and covers the age range from 10-24 years. Interest in further participation is indicated by the willingness of participants to book for a revisit. However, as observed in other studies, $66.5 \%$ of attendees are within the age range of $15-19$ years and $60.9 \%$ of unmarried adolescents who failed to book for a re-visit, are of the age range of 10-14 years. This observation clearly indicates that adolescents within this age group do not fully understand their problems and consequence of their behaviour (Joshi et al., 2006). We observed that more females visited this facility than their male counterparts. This was similarly reported by Joshi et al. (2006) in a study of Indian adolescents, where $35 \%$ voluntary clinic attendance was observed among males compared to $43 \%$ of females.

This present study also observed a close relationship between health seeking behaviour and peer influence. Over sixty-five percent of adolescents who visited the facility got their information from friends, with parents contributing less than $1.3 \%$. This pattern is similar to some studies relating to adolescent sexuality (Miriam et al., 1999; Kemp, 2000). This reflects the fact that either most parents are yet to recognise the importance of discussing critical health and sex education with their children or most adolescents still have more confidence in their peers. This trend has also been documented in developed countries (Barker et al., 2005). 
This present study indicated that majority of attendees $(78 \%)$ presented with general health problems; this might explain the reason for the high percentage of non-booking recorded in this study. Most general health issues could have been solved at a single visit, or the individuals concern might opt for a more specialised or preferred treatment alternatives having weighed their options at the first visit. The data generated shows that sexual health issues including reproductive tract infections, menstrual disorders and pregnancy options accounted for $9.7 \%$; $6.6 \%$; $2.5 \%$ and $0.9 \%$ of overall attendance respectively. This finding is contrary to report by Joshi et al. (2006), who stated that menstrual disorders alone accounted for $30 \%$ of clinic visit in a study in India. However, the study indicated that the lowest attrition (un-booking) occurred in adolescents presenting with pregnancy options, menstrual disorders and reproductive tract infections (20\%;27\% and $38.4 \%$ respectively), thereby indicating that reproductive issues and perceived threat to reproduction are taken seriously among Nigerians who would be willing to explore every available alternatives to seeking help.

We found that only a quarter of the never married adolescents reported to have ever had sexual intercourse and a high proportion of them reported not sexually active during this investigation. This was contrary to the finding of a previous study which reported that in many countries, the most people: married or unmarried initiate sexual activity during adolescence (Mensch et al., 1998). In a study of 410 adolescent girls in a rural community in Rivers state, Nigeria, $62 \%$ of them had initiated sexual intercourse (Kemp, 2000; FMOH, 2003) and about $14 \%$ of the girls initiated sexual intercourse by age 10-14 years (FMOH, 2003). A similar study in Rivers state reported that $78.8 \%$ of the 768 adolescents aged 14-21 years had been sexually exposed and the mean age at sexual initiation was 15.04 years with $2 \%$ of them having initiated sex at the age of 12 (Okpani and Okpani, 2000). In Calabar, Cross River State of Nigeria, the mean age at sexual initiation was 13.7 years (Etuk et al., 2004). In Delta State, a UNFPA sponsored baseline survey which included 1013 adolescents showed that $34.4 \%$ of adolescents aged between $15-19$ years have had sex (Patrick, 2007) , while another study of 516 secondary school students also in Delta state showed that $69 \%$ of them have been sexually initiated (Oboro and Tabowei, 2003).

The low proportion of adolescents that had initiated sex at the time of this study (25.5\%) might be due to under-reporting by the adolescents. It could also be they were not contented to discussing reproductive health issues as reported by PATH (1999). It has been found that adolescents might also experience resistance or hostility and bad attitudes from adults when they attempt to obtain the reproductive health information and services. These circumstances can be attributed to a number of social, religious, cultural, economic, and gender-related factors (Potts et al., 2001). It may not be misleading to state that these factors are present in Nigeria where this study was conducted. However the mean age of initiating sex (15 years) is comparable with findings of Okpani and Okpani (2000).

A high percentage of those that were sexually active engaged in sexual intercourse at least once a week. This was consistent with a study that revealed that Nigerian adolescents, like their counterparts around the globe are sexually active (Oransaye and Odiase, 1983). It was observed that the factors that were significantly associated with re-visit to the health facility among the youths were religion, ethnicity, who the adolescent live with, reasons for visiting the facility, whether adolescent have ever had sex, whether they were sexually active, use of contraceptive for the last intercourse and the preferred/adopted contraceptive option. However, after logistic regression modelling of the factors, only three of them were found to act as the determinants of adolescents' ability to re-visit the health care facility. The three factors were the preferred/adopted contraceptive during last visit, sexual status and religion.

Muslim adolescents were about twice more likely to book for a re-visit than Christian adolescents, and could be thrice as high. Also, non- sexually active adolescents were less likely to book for a re-visit to the clinic after first consultation than sexually active ones. These findings were consistent with those of Creel and Perry (2003) which revealed that circumstances attributed to a number of social, religious, cultural, economic, and gender-related factors affect utilization of adolescent friendly clinic. 
Adolescents who adopted abstinence as their contraceptive option during the last visit were less likely to book for a re-visit to the adolescent friendly clinic than those who prefer condom or pill. This could be that those who did not book for re-visits felt that they were not adequately benefiting from the services rendered at the clinic. More varieties of adolescent friendly services that meet the needs of all adolescents should be introduced at the centre.

\section{CONCLUSION/RECOMMENDATION}

This study based on observed pattern at an adolescent clinic, had clearly demonstrated the deficiency in information dissemination in our environment. Majority of attendees still perceive this center as no different from conventional clinics, thereby presenting mainly with general health problems. The reliance of adolescents on their peers to obtain vital information regarding their health is not satisfactory, and capable of defeating the millennium development goal. This requires a more proactive approach on the part of parents, health professionals, non-governmental organizations and the media in disseminating accurate information and de-mystifying issues relating to sexual health and adolescents.

\section{REFERENCES}

Barker G, Olukoya A and Aggleton P (2005). Young People, Social Support and Help-Seeking. Int J Adolesc Med Health. 17: 315-36.

Etuk SJ, Ihejieamaizu EC and Etuk IS (2004). Female Adolescent Sexual Behaviour in Calabar, Nigeria. Niger Postgrad Med J. 1: 269-73.

FMOH (2004). HIV/Syphilis Sentinel Survey Results, 2003, Abuja Nigeria: Ministry of Health: Pp:

Joshi BNM Chauhan SL, Donde UM, Toyambake VH, Gaikwad NS, and Bhadovic V (2006). Reproductive Health Problems and Help Seeking Behaviour among Adolescents in Urban India. Indian J Pediatr. 73:509-513.

Kemp JR. (2000). A Study of Sexual Behaviour and Reproductive Health of Adolescent Girls in South East, Nigeria. PhD thesis. University of Liverpool.

Creel LC and Perry RJ (2003). Improving the Quality of Reproductive Health Care for Young People. Population Council and Population Reference Bureau. New Perspectives on Quality of Care. 1: 2-8.

Mensch BS, Bruce J and Greene ME (1998). The Uncharted Passage; Girls Adolescence in the Developing World; Population Council. 3: 46-48.

Miriam JT, Friday EO, Francesca OO, Elisha PR, Paul CH, Kris H and Joan K (1999). Perception of Sexual Behaviour and Knowledge about Sexually Transmitted Diseases among Adolescents in Benin-city, Nigeria. Int Fam Plann Perspect. 25: 186-190.

Nath A and Garg S (2008). Adolescent Friendly Health Services in India: A Need of the Hour; Indian J Med Sci. 62: 465-472.

Oboro VO and Tabowei TO (2003). AIDS Prevention Programmes and Sexual Behaviour among Secondary School Adolescents in Delta state, Nigeria. Trop J Obst Gynaecol. 20:1-2.

Okpani AOU and Okpani JU (2000). Sexual Activity and Contraceptive Use among Female Adolescents. A report from Port Harcourt, Nigeria. Afr J. Reprod Health. 4 : 40-47.

Oransaye AU and Odiase GI (1983). Attitudes towards Abortion and Contraception among Secondary School Girls in Benin City. Internatn $J$ Gynaecol and Obst. 21: 423-426.

PATH (Program for Appropriate Technology in Health (1999). Improving Interactions with Clients: A key to High-quality Services. Outlook. 17: 3-5.

Patrick I (2007). Adolescent Sexual and Reproductive Health in the Niger Delta Region of Nigeria: Issues and Challenges. Afr $J$ Reprod Health. 11:9-12.

Potts Y, Gillies M and Wood S (2001). Lack of Mental Well-being in 15year Olds: An Undisclosed Iceberg? Fam Pract. 18: 95-100.

Segun T (2006). Factors affecting Adolescent Sexuality among in-school Adolescents in Lagos:Training on Sexual Health Research, Geneva Switzerland. http://www.gfmer.ch/Medical education En/PGC SH/Segun 2006. Accessed May 2006

UNESCO (1999). Characteristics of YouthFriendly Services: Adapted from FOCUS on Young Adults: Making Reproductive Health Services Youth Friendly, Washington D.C. 1:1-6. 
WHO (2002). Adolescent Friendly Health Services: An Agenda for Change. Geneva: Pp: 518. 